\title{
Study of the Effect of Quenching on Microstructural and Magnetic Properties of Cu-Doped Mg-Ferrite
}

\author{
Apurba Poddar, ${ }^{1}$ Suman Halder ${ }^{D},{ }^{1}$ S.I. Liba, ${ }^{2}$ Sheikh Manjura Hoque, ${ }^{2}$ \\ and Shibendra Shekher Sikder ${ }^{1}$ \\ ${ }^{1}$ Department of Physics, Khulna University of Engineering and Technology, Khulna-9203, Bangladesh \\ ${ }^{2}$ Material Science Division, Atomic Energy Center, Dhaka-1000, Bangladesh
}

Correspondence should be addressed to Suman Halder; shalder1@kent.edu

Received 26 September 2021; Revised 4 February 2022; Accepted 10 February 2022; Published 27 February 2022

Academic Editor: Maheswar Nayak

Copyright (c) 2022 Apurba Poddar et al. This is an open access article distributed under the Creative Commons Attribution License, which permits unrestricted use, distribution, and reproduction in any medium, provided the original work is properly cited.

\begin{abstract}
$\mathrm{Mg}_{1-\mathrm{x}} \mathrm{Cu}_{\mathrm{x}} \mathrm{Fe}_{2} \mathrm{O}_{4}(x=0.0-0.5)$ was prepared by the double sintering ceramic method, which sintered at $1100^{\circ} \mathrm{C}$ and $1200^{\circ} \mathrm{C}$ for 3 hours and investigated for structural, microstructural, and magnetic properties as a function of the Cu content and cooling process. XRD analysis of $1100^{\circ} \mathrm{C}$ sintered samples revealed that all the samples were crystallized in a single-phase cubic spinal structure. The microstructural and magnetic properties of slow cooled (furnace-cooled) and fast cooled (quenched) $\mathrm{Mg}$-Cu ferrites have been studied using the scanning electron microscope (SEM), vibrating sample magnetometer (VSM), and Mössbauer spectroscopy after sintering at $1200^{\circ} \mathrm{C}$. Homogeneous coaxial grains did not form for any furnace-cooled samples, while for the quenched sample, homogeneous grains were clearly visible even without doping with $\mathrm{Cu}$. Substantial grain growth was witnessed by the samples with higher copper content for both cooling conditions, whereas quenched samples possessed a smaller grain size compared to furnace-cooled samples. The saturation magnetization experienced a higher value for quenched samples compared to furnace-cooled samples with increasing $\mathrm{Cu}$ content except for $x=0.4$. The sextet pattern of Mössbauer spectroscopy confirmed all the samples were ferromagnetic in nature. Chemical shift, quadrupole shift, hyperfine field, and site occupancy of $\mathrm{Fe}^{3+}$ were also obtained using Mössbauer spectroscopy.
\end{abstract}

\section{Introduction}

Magnetic ferrites have gained a lot of attention from scientists, engineers, and industrialists due to their extraordinary physical and chemical properties along with their super surface activity. Ferrites that contain iron oxide as a significant constituent are considered one of the crucial categories of magnetic materials. Magnetic ferrites have an enormous impact on broad range of applications in diverse areas such as electrical and electronic industries, microwave and satellite communications technology, digital recording devices, and biomedical [1-6]. Their versatile properties not only make them suitable for a wide range of applications but also make them appropriate materials as an alternative to the rear earth-based permanent magnetic materials.
Magnesium copper ferrites are ceramic-type magnetic materials with very high resistivity, high permeability, and low eddy current losses leading to applications in the highfrequency environment. Copper-doped magnesium ferrites are partially inverted spinel ferrites, and basically, this doping causes a rearrangement of $\mathrm{Fe}^{3+}$ ions into the two preexisting octahedral and tetrahedral sites. The magnetic interaction and cation distribution between tetrahedral (A) and octahedral (B) lattice sits are responsible for the physical, electrical, and magnetic properties of spinel ferrites. The cation distribution of ferrite is influenced by many factors such as the synthesis method, cations substitution, and postpreparation heat treatments [7-9]. Moreover, the cooling rate from high temperatures can change the cation distribution of the ferrites, leading to modifying the room 
temperature phase distribution, microstructure, and magnetic properties [10-15].

$\mathrm{Mg}_{1-\mathrm{x}} \mathrm{Cu}_{\mathrm{x}} \mathrm{Fe}_{2} \mathrm{O}_{4}$ prepared using various methods has been extensively investigated to revile the effect of the $\mathrm{Cu}$ substitution and heat treatment on the structural, electrical, and magnetic properties to enhance the properties for application to various technical devices [16-20]. In most of the previous studies which investigated the heat treatment, the samples were cooled very slowly to allow the cations to migrate their equilibrium position at room temperature [21-24]. However, it is required to know fast cooling can affect the microstructure and magnetic properties of the copper-doped magnesium ferrites.

In this present work, $\mathrm{Mg}_{1-\mathrm{x}} \mathrm{Cu}_{\mathrm{x}} \mathrm{Fe}_{2} \mathrm{O}_{4}(x=0.0,0.1,0.2$, $0.3,0.4$, and 0.5 ) ferrites were synthesized by the standard double sintering ceramic method. The effect of $\mathrm{Cu}$ substitution on the structural properties of $\mathrm{Mg}-\mathrm{Cu}$ ferrites annealed at $1100^{\circ} \mathrm{C}$ has been investigated using XRD. The microstructure and magnetic properties of the furnacedcooled and quenched samples after annealing at $1200^{\circ} \mathrm{C}$ were studied using SEM, Mössbauer spectroscopy, VSM, and the results were compared.

\section{Materials and Experimental Methods}

The $\mathrm{Mg}_{1-\mathrm{x}} \mathrm{Cu}_{\mathrm{x}} \mathrm{Fe}_{2} \mathrm{O}_{4}(x=0.0,0.1,0.2,0.3,0.4$, and 0.5$)$ was prepared by the double sintering ceramic method. The analytical grade with the purity of $99.99 \%$ magnesium oxide $(\mathrm{MgO})$, copper oxide $(\mathrm{CuO})$, and ferric Oxide $\left(\mathrm{Fe}_{2} \mathrm{O}_{3}\right)$ were mixed using an agate mortar and pestle according to their molecular weight. Stoichiometric amounts of required powder were mixed thoroughly by the ball milling method for 6 hours and then pressed into disc-shaped samples. The disc-shaped samples were presintered at $900^{\circ} \mathrm{C}$ for 6 hours. The presintered samples were then crushed and milled for 6 hours in distilled water. The mixture was dried, and a few drops of polyvinyl alcohol were added. The resulting powders were then pressed into disk-shaped and toroid-shaped samples, and finally, they were sintered at $1100^{\circ} \mathrm{C}$ and $1200^{\circ} \mathrm{C}$ for 3 hours. The $1200^{\circ} \mathrm{C}$ sintered samples were cooled through two different cooling processes. One is furnace cooling (samples were kept inside the closed furnace until coming to room temperature) and another is water quenching (samples were took out from the furnace instantly after sintering and quenched in water).

The structural and physical characterization of the Mg$\mathrm{Cu}$ ferrite was carried out by Philips (PW 3040) X' Pert PRO $\mathrm{X}$-ray diffractometer with $\mathrm{CuK} \alpha$ radiation (wavelength $\lambda=1.5406 \AA$ ). The scanning electron micrograph of the samples was taken on FEITSCH@Laboratte, model 17:202, no. 1030, SEM machine. Magnetization measurements were carried out by a vibrating sample magnetometer (VSM) (ADE, model EV7) at room temperature in the magnetic field range $\pm 15 \mathrm{KOe}$. Mössbauer spectroscopy with a model VT400 was used to acquire Mössbauer spectra by using a linear velocity transducer that moves a ${ }^{57}$ Co source in a $\mathrm{Rh}$ matrix, which decays to an excited state of ${ }^{57} \mathrm{Fe}$ that decay to ground state by emitting $14.4 \mathrm{keV} \quad \gamma$-rays.
Mössbauer spectra were analyzed by using WMOSS $4 \mathrm{R}$ software with the fast relaxation module.

\section{Results and Discussion}

3.1. XRD Analysis. The X-ray diffraction (XRD) patterns for the series of samples $\mathrm{Mg}_{1-\mathrm{x}} \mathrm{Cu}_{\mathrm{x}} \mathrm{Fe}_{2} \mathrm{O}_{4}(x=0.0-0.5)$ sintered at $1100^{\circ} \mathrm{C}$ for 3 hours are shown in Figure 1. A phase analysis using the X-ray technique was performed to confirm the formation of a single-phase cubic spinel structure with no extra lines corresponding to any other crystallographic phase. The results obtained from the XRD pattern for all the samples of $\mathrm{Mg}_{1-\mathrm{x}} \mathrm{Cu}_{\mathrm{x}} \mathrm{Fe}_{2} \mathrm{O}_{4}$ with the (h $k$ l) values corresponding to the diffraction peaks of different planes (220), (311), (400), (422), (511), (440), and (533) which represent either odd or even indicating the samples are spinel cubic phase. Peaks are matched with an indexed of reference pattern: 88-1936 for magnesium ferrite and 77-0010 for copper ferrite $[25,26]$. The XRD patterns analysis indicated that the studied $\mathrm{Mg}$-Cu ferrites samples have spinel cubic structures with a single phase.

The lattice parameter is calculated from the relation $a_{o}=$ $\lambda d / 2 \sin \theta$, where $d=\sqrt{h^{2}+k^{2}+l^{2}}$, and is given in Table 1 . An increase in lattice parameter of $\mathrm{Mg}_{1-\mathrm{x}} \mathrm{Cu}_{\mathrm{x}} \mathrm{Fe}_{2} \mathrm{O}_{4}$ is observed with the addition of $\mathrm{Cu}$ content in the lattice. These increases can be attributed to the ionic size difference, since the unit cell has to expand when larger $\mathrm{Cu}^{2+}$ ions with ionic radii $0.73 \AA$ tend to replace $\mathrm{Mg}^{2+}$ ions with radii $0.65 \AA$. There exists a correlation between the ionic radius and the lattice constant; the increase of the lattice constant is proportional to the increase of the ionic radius [27].

Density plays a vital role in controlling the properties of polycrystalline ferrites. The X-ray density $\left(\rho_{x}\right)$ is calculated using the equation $\rho_{x}=8 M / \mathrm{Na}^{3}$, where $M$ is the molecular weight, $\mathrm{N}$ is Avogadro's number. The bulk density $\left(\rho_{\beta}\right)$ is calculated by using the mass and bulk volumes of the samples. The percentage of porosity for $\mathrm{Mg}-\mathrm{Cu}$ ferrites is also calculated from the value of X-ray density and bulk density using the equation $\% P=1-\rho_{\beta} / \rho_{x}$. The value of $\mathrm{X}$-ray density, bulk density, and the percentage of porosity is given in Table 1. From Table 1, it is shown that the X-ray density increases slightly before decreasing slowly with substituent concentration since it depends on the lattice parameter and molecular weight of $\mathrm{Mg}-\mathrm{Cu}$ ferrite. The highest X-ray density is observed for $x=0.3\left(\rho_{x}=4.782 \mathrm{~g} /\right.$ $\left.\mathrm{cm}^{3}\right)$ and the lowest density is observed at $x=0.00\left(\rho_{x}\right.$ $=4.373 \mathrm{~g} / \mathrm{cm}^{3}$ ). The bulk density is found to increase with the $\mathrm{Cu}$ content. It is also observed that the bulk density is lower than the corresponding X-ray density. This may be due to the existence of pores, which were formed and developed during the sample preparation or sintering process [28]. The increase in X-ray density is also because of the difference in ionic radii between $\mathrm{Mg}$ and $\mathrm{Cu}$. On the other hand, increasing the $\mathrm{Cu}$ content in $\mathrm{Mg}-\mathrm{Cu}$ ferrites can achieve a significant decrease in porosity. It is observed that the lowest porosity is obtained for the sintering temperature of $1100^{\circ} \mathrm{C}$ for $x=0.5$, which is $23.789 \%$, and the highest porosity is seen to occur when $x=0.1$. The range of porosity from $49 \%$ to $23 \%$ indicated that the samples are highly porous. 


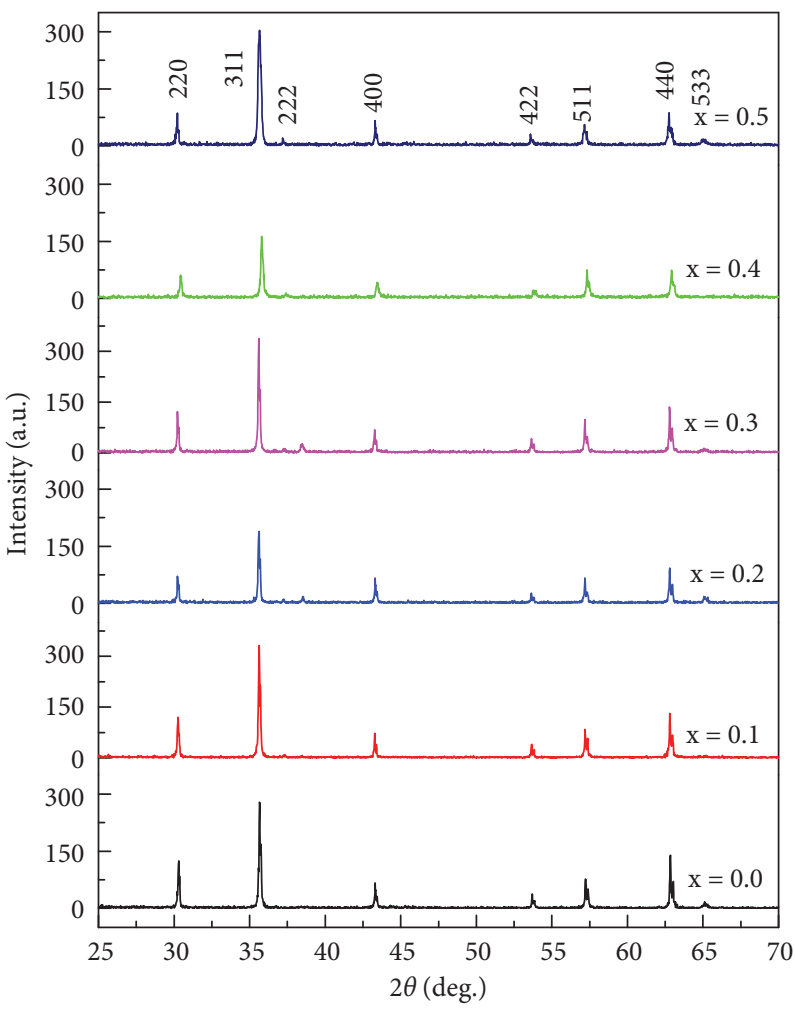

Figure 1: X-ray diffraction patterns for $\mathrm{Mg}_{1-\mathrm{x}} \mathrm{Cu}_{\mathrm{x}} \mathrm{Fe}_{2} \mathrm{O}_{4}(x=0.0-0.5)$ sintered at $1100^{\circ} \mathrm{C}$ for 3 hours.

TABLE 1: Lattice parameter, X-ray density, bulk density, and porosity for different compositions of the sample $\mathrm{Mg}_{1-\mathrm{x}} \mathrm{Cu}_{\mathrm{x}} \mathrm{Fe}_{2} \mathrm{O}_{4}$ sintered at $1100^{\circ} \mathrm{C}$.

\begin{tabular}{lcccc}
\hline Copper content & Lattice parameter, $a_{\mathrm{o}}(\AA)$ & $\mathrm{X}$-ray density, $\rho_{x}\left(\mathrm{~g} / \mathrm{cm}^{3}\right)$ & Bulk density, $\rho_{\beta}\left(\mathrm{g} / \mathrm{cm}^{3}\right)$ & Porosity, $\mathrm{P}(\%)$ \\
\hline$x=0.0$ & 8.764 & 4.373 & 2.477 & 4305 \\
$x=0.1$ & 8.773 & 4.556 & 2.663 & 49.456 \\
$x=0.2$ & 8.775 & 4.722 & 3.126 & 43.604 \\
$x=0.3$ & 8.778 & 4.782 & 3.463 & 34.629 \\
$x=0.4$ & 8.779 & 4.717 & 3.414 & 26.584 \\
$x=0.5$ & 8.781 & 4.481 & & 23.790 \\
\hline
\end{tabular}

3.2. SEM Study. Figures 2(a) and 2(b) represent the microstructures and particle size distribution of furnace-cooled and quenched $\mathrm{Mg}_{1-\mathrm{x}} \mathrm{Cu}_{\mathrm{x}} \mathrm{Fe}_{2} \mathrm{O}_{4}(x=0.0-0.5)$ ferrites after sintered at $1200^{\circ} \mathrm{C}$, respectively. The average particle diameter $\langle\mathrm{D}\rangle$ is estimated from the histograms and presented in the figure insets. It is clear that the microstructure of $\mathrm{Mg}$ $\mathrm{Cu}$ ferrites strongly depends on the amount of $\mathrm{Cu}^{2+}$ present in the samples. A gradual increase in grain size distribution is observed with an increase in $\mathrm{Cu}$ content. $\mathrm{Cu}^{2+}$ influences the microstructure $\mathrm{Mg}-\mathrm{Cu}$ ferrites by the formation of a liquid phase during sintering. It facilities grain growth by increasing the cation interdiffusion rate due to its segregation to the grain boundaries [29]. It can be noticed that proper densification was not attained for slow cooled (furnace-cooled) samples until $x=0.5$, while for fast cooled samples (quenched), densification was fairly higher even for $x=0.0$. It is seen from the figure that the samples up to $x=0.2$ show a homogeneous microstructure with small grain size in both cooling conditions. However, considerable abnormal and inhomogeneous grain growth is observed with sample $x=0.3,0.4$, and 0.5 . Moreover, the intergranule porosity is observed to reduce with the increasing content of $\mathrm{Cu}$. This grain growth that occurs for $x>0.2$ could be due to the dominance of thermal energy-generated driving force over the force exerted by the pores. Besides, the inhomogeneous deriving force of the grain boundary in each grain results in a nonuniform grain size distribution and vice versa [30]. The major difference between the furnace-cooled and quenched samples is the grain size for the respective $\mathrm{Cu}$ content. The quenched samples are characterized by smaller particles compared to the furnace-cooled samples. Quenching of microstructured materials preserves its microstructural features developed at high temperature, whereas microstructures could slowly transform to thermodynamically stable structure (lower Gibbs free energy) for the slowly cooled materials. It is well known that the small grains are energetically less stable than the large grain for their higher specific surface area. Therefore, the 

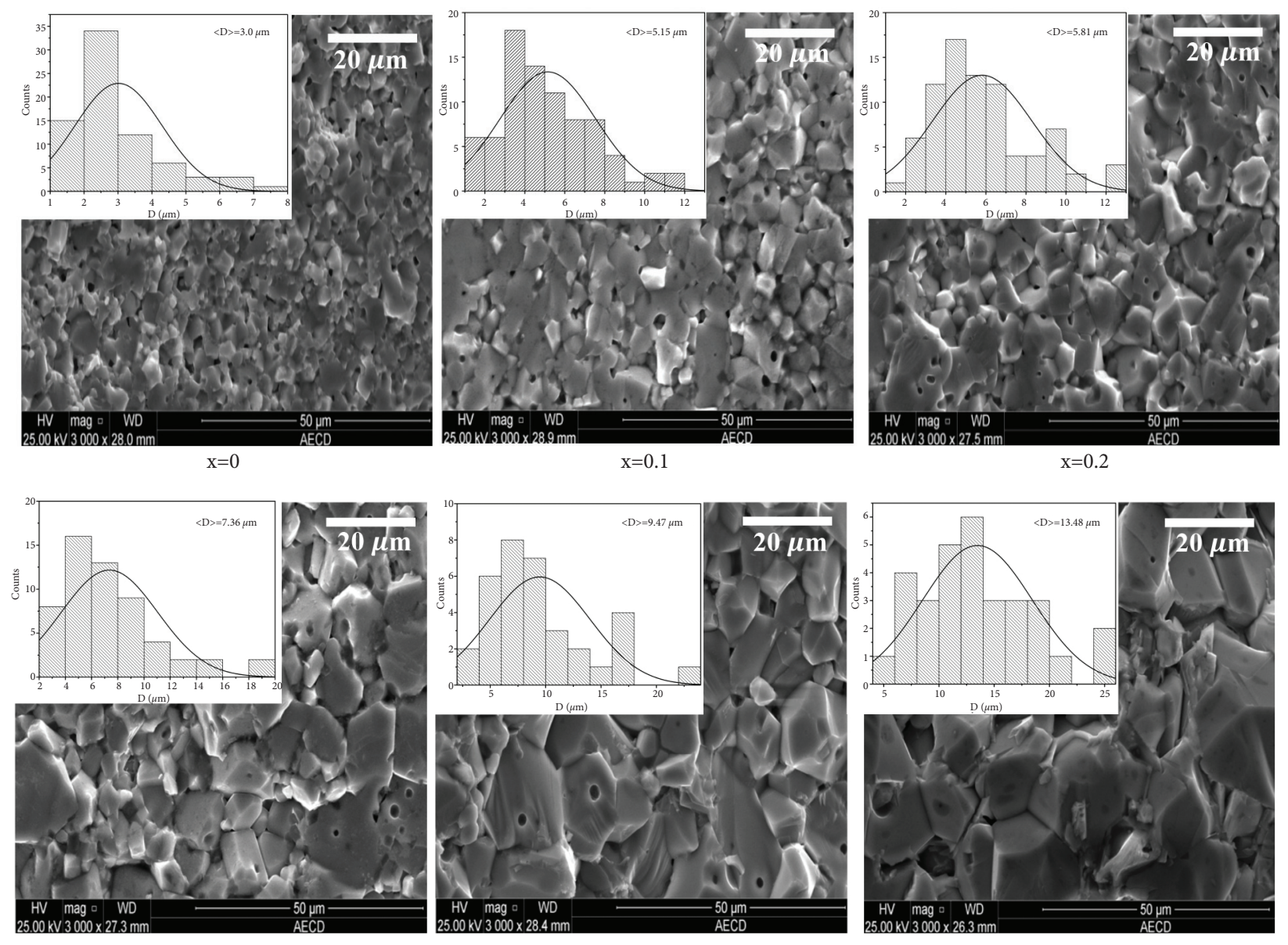

(a)

$\mathrm{x}=0.5$

Figure 2: Continued. 


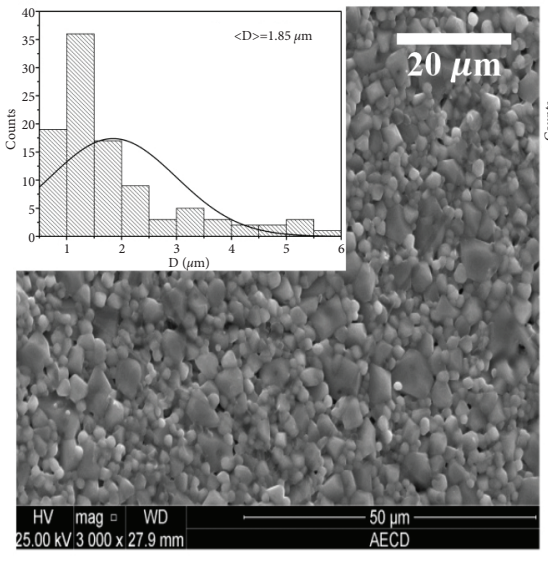

$\mathrm{x}=0.0$

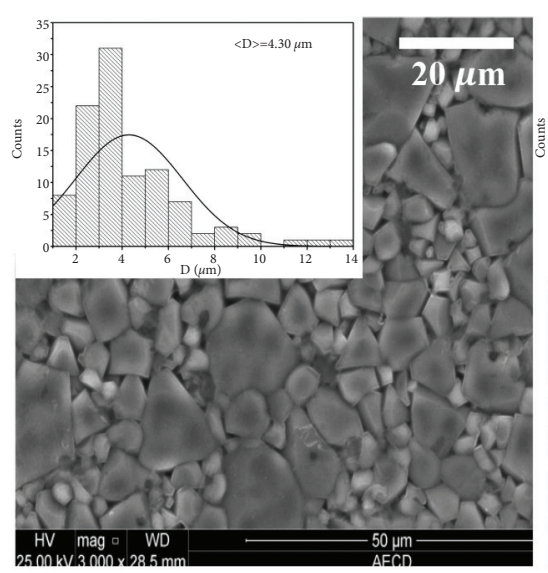

$\mathrm{x}=0.3$

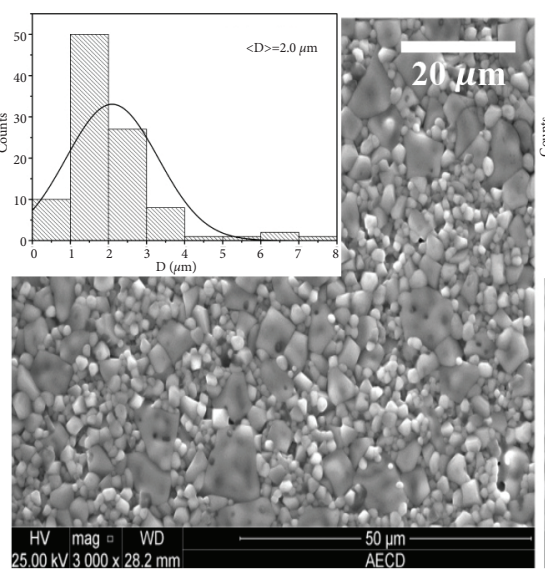

$\mathrm{X}=0.1$
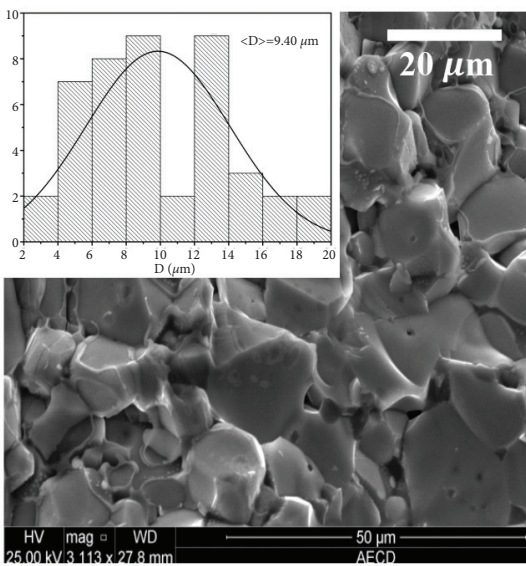

$\mathrm{x}=0.4$

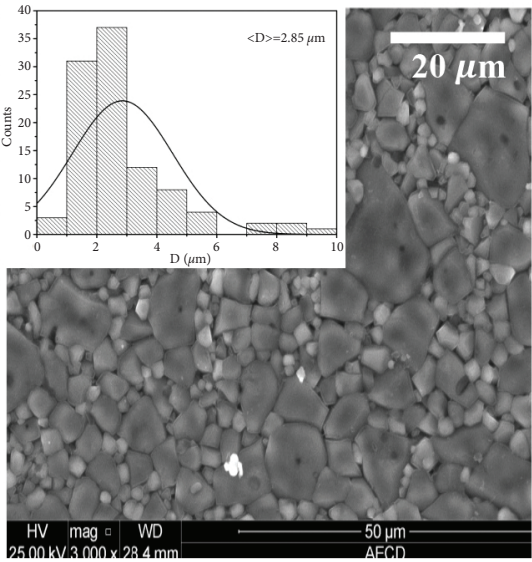

$\mathrm{x}=0.2$

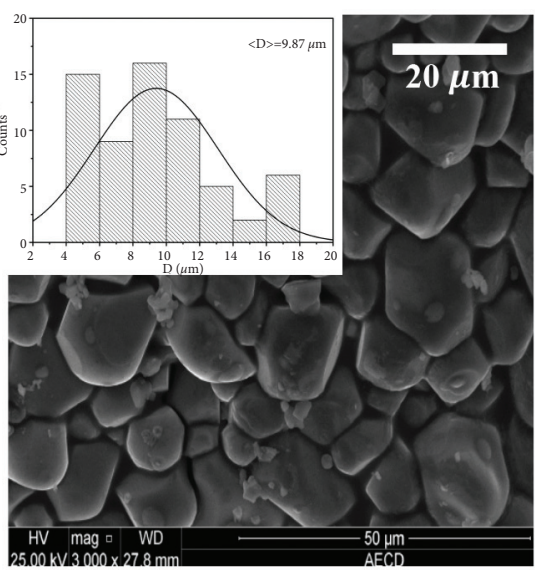

$\mathrm{x}=0.5$

(b)

FIGURE 2: SEM micrograph of (a) furnace-cooled and (b) quenched $\mathrm{Mg}_{1-\mathrm{x}} \mathrm{Cu}_{\mathrm{x}} \mathrm{Fe}_{2} \mathrm{O}_{4}(x=0-0.5)$ samples. Insets show the particle size distribution fitted with lognormal function.

microstructure achieved for the quenched materials is then said to be metastable.

\subsection{Magnetic Properties Measurement. The room tempera-} ture magnetic hysteresis $(\mathrm{M}-\mathrm{H})$ loop of the samples (furnace-cooled and quenched from $1200^{\circ} \mathrm{C}$ ) has been measured and is shown in Figures 3(a) and 3(b). The samples exhibited a minimal hysteresis effect with small coercivity, which indicates that all the samples belong to the family of soft ferrites. The magnetization is saturated with an applied field of around $5 \mathrm{kOe}$ of all samples. Figures $3(\mathrm{c})$ and $3(\mathrm{~d})$ and Table 2 represent the saturation magnetization $\left(M_{\mathrm{s}}\right)$, coercivity $\left(H_{\mathrm{c}}\right)$, and remanence $\left(M_{\mathrm{r}}\right)$ obtained from VSM at room temperature for furnace-cooled and quenched samples. In the case of quenched samples, it is observed that the value of $M_{\mathrm{s}}$ gradually increases with increasing $\mathrm{Cu}$ content, becomes a maximum for $x=0.3$, and decreases slightly at $x=0.5$. The saturation magnetization dramatically soared at $x=0.4$, which might be attributed to experimental error. The saturation magnetization is found to be increased because of the super exchange interaction between the antiparallel magnetic moment of A site and B site strengthened because of the substitution of $\mathrm{Cu}$ ion in $\mathrm{Mg}$-Cu ferrite. Besides, the magnetization decreased after $x=0.3$, maybe for the decrease of the fraction of $\mathrm{Cu}^{2+}$ ion of the $\mathrm{A}$ site and the fraction of the $\mathrm{Mg}^{2+}$ ions being more on the $\mathrm{B}$ site. This similar behavior has been reported in several works subjected to the study of substitution influence [31, 32]. For furnace-cooled samples, the saturation magnetization for pure $\mathrm{Mg}$-ferrite is $37.28 \mathrm{emu} / \mathrm{g}$, which decreases to $30.22 \mathrm{emu} / \mathrm{g}$ for $x=0.1$, starts to increase, and reaches $42.34 \mathrm{emu} / \mathrm{g}$ at $x=0.5$. This variation with $\mathrm{Cu}$ content can be explained based on cation distribution [33].

Moreover, it is evident in Figure 3(c) and Table 2 that the quenched samples possess higher saturation magnetization than the furnace-cooled samples. Due to the high-temperature sintering, nonmagnetic $\mathrm{Mg}^{2+}$ ions migrated to the $\mathrm{A}$ site, allowing magnetic $\mathrm{Fe}^{3+}$ ions to have $\mathrm{B}$ sites. Hence, the magnetization on the $B$ site increases while A site magnetization decreases, causing increases in net magnetization. Therefore, after a height temperature sintering, the quenching results whatever that the cation distribution at high temperature get frozen and remain same even at room 


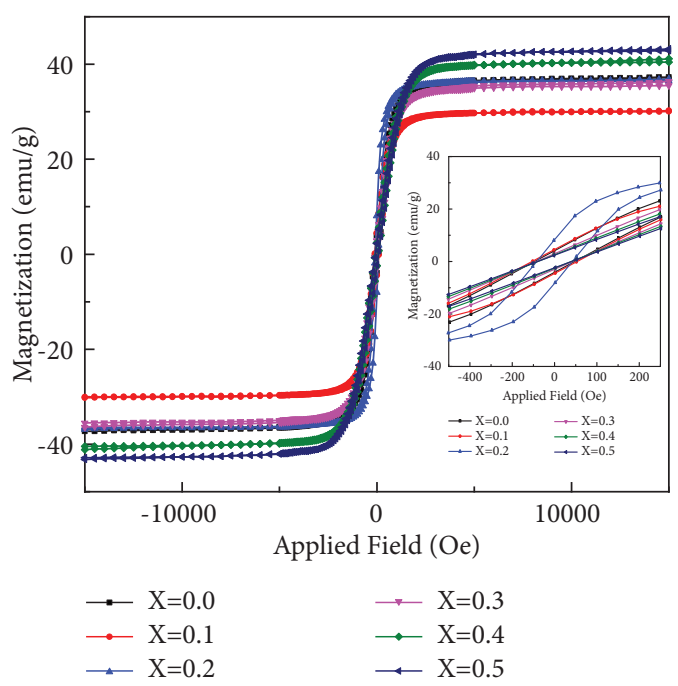

(a)

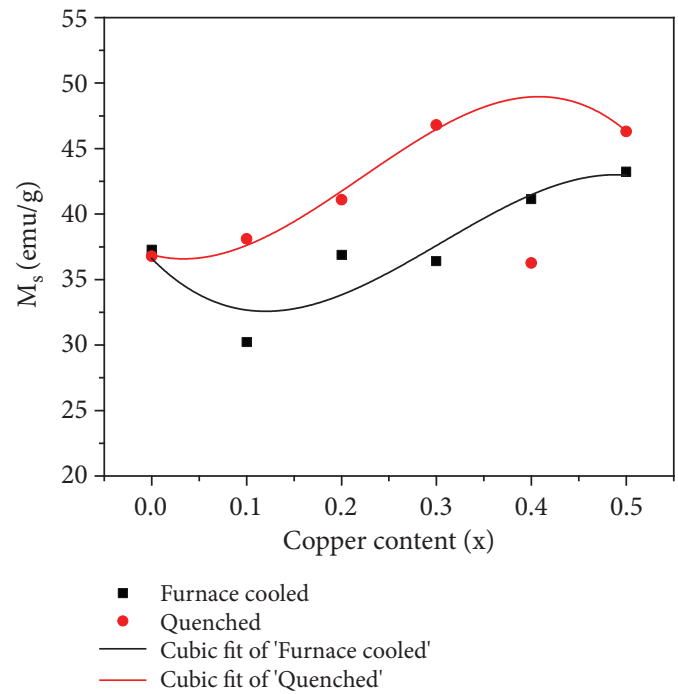

(c)

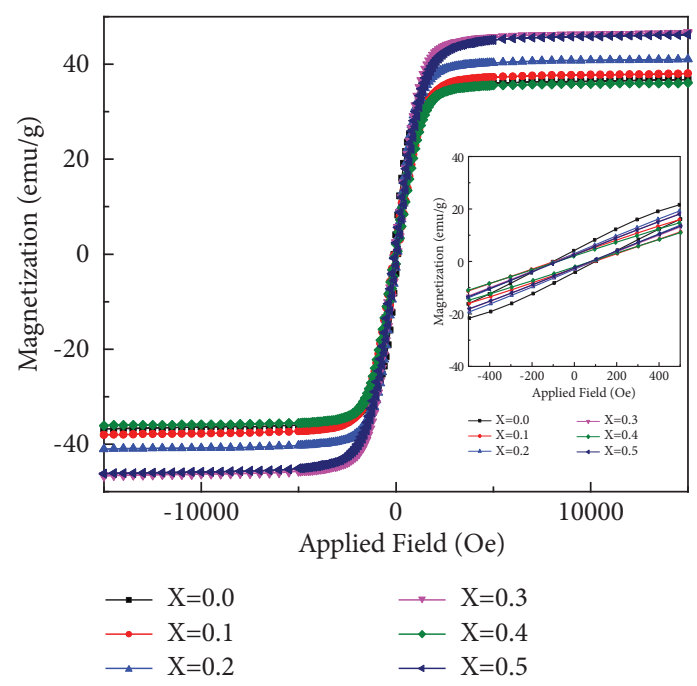

(b)

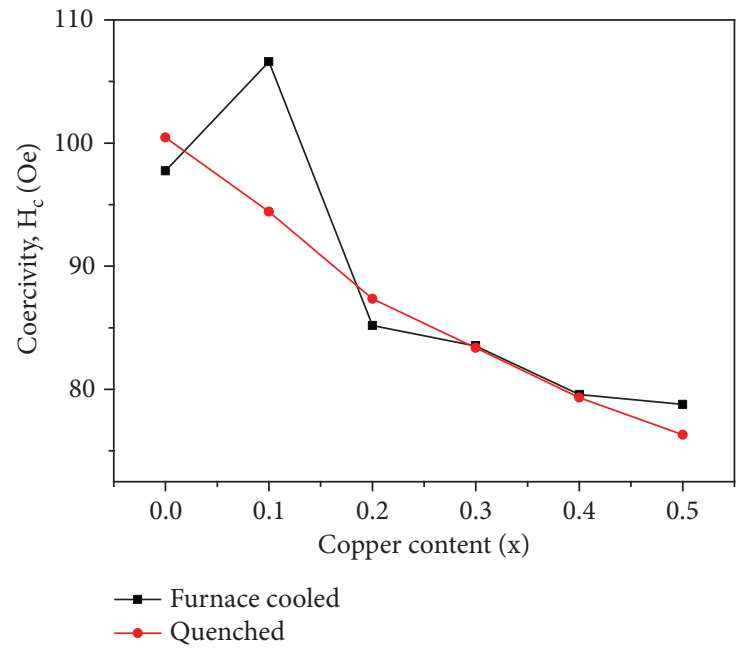

(d)

Figure 3: M-H curve of (a) furnace-cooled and (b) quenched $\mathrm{Mg}_{1-\mathrm{x}} \mathrm{Cu}_{\mathrm{x}} \mathrm{Fe}_{2} \mathrm{O}_{4}(x=0-0.5)$ samples. Variation of (c) saturation magnetization and (d) coercivity of furnace-cooled and quenched $\mathrm{Mg}-\mathrm{Cu}$ ferrites with $\mathrm{Cu}$ content.

TABLE 2: Saturation magnetization, coercivity, and remanence measured by VSM at room temperature for furnace-cooled and quenched $\mathrm{Mg}_{1-\mathrm{x}} \mathrm{Cu}_{\mathrm{x}} \mathrm{Fe}_{2} \mathrm{O}_{4}$ after sintering at $1200^{\circ} \mathrm{C}$

\begin{tabular}{|c|c|c|c|c|c|c|c|c|}
\hline \multirow[t]{2}{*}{ Copper content } & \multicolumn{2}{|c|}{$\begin{array}{l}\text { Saturation magnetization, } \\
\qquad M_{\mathrm{s}}(\mathrm{emu} / \mathrm{g})\end{array}$} & \multicolumn{2}{|c|}{ Coercivity, $H_{c}(\mathrm{Oe})$} & \multicolumn{2}{|c|}{$\begin{array}{l}\text { Remanent magnetization, } \\
\qquad M_{\mathrm{r}}(\mathrm{emu} / \mathrm{g})\end{array}$} & \multicolumn{2}{|c|}{$M_{\mathrm{r}} / M_{\mathrm{s}}$} \\
\hline & Furnace-cooled & Quenched & Furnace-cooled & Quenched & Furnace-cooled & Quenched & Furnace-cooled & Quenched \\
\hline$x=0.0$ & 37.28 & 36.77 & 97.73 & 100.45 & 3.98 & 4.18 & 0.11 & 0.11 \\
\hline$x=0.1$ & 30.22 & 38.11 & 106.59 & 94.43 & 4.57 & 2.61 & 0.15 & 0.07 \\
\hline$x=0.2$ & 36.88 & 41.12 & 85.18 & 87.34 & 8.34 & 2.98 & 0.23 & 0.07 \\
\hline$x=0.3$ & 36.41 & 46.82 & 83.52 & 83.38 & 2.96 & 2.64 & 0.08 & 0.06 \\
\hline$x=0.4$ & 41.14 & 36.26 & 79.57 & 79.32 & 2.54 & 2.11 & 0.06 & 0.06 \\
\hline$x=0.5$ & 43.23 & 46.37 & 78.77 & 76.31 & 2.39 & 2.47 & 0.06 & 0.05 \\
\hline
\end{tabular}

temperature. On the other hand, in the furnace-cooled samples, the cations are redistributed while cooling slowly. This redistribution resulted in lower saturation magnetization for the furnace-cooled samples. This higher saturation magnetization of $\mathrm{Mg}$-Cu ferrite obtained through quenching is the main finding of this work. The coercivity is found to decrease with the addition of $\mathrm{Cu}^{2+}$ content for both quenched and furnace-cooled samples except for $x=0.1$ in 

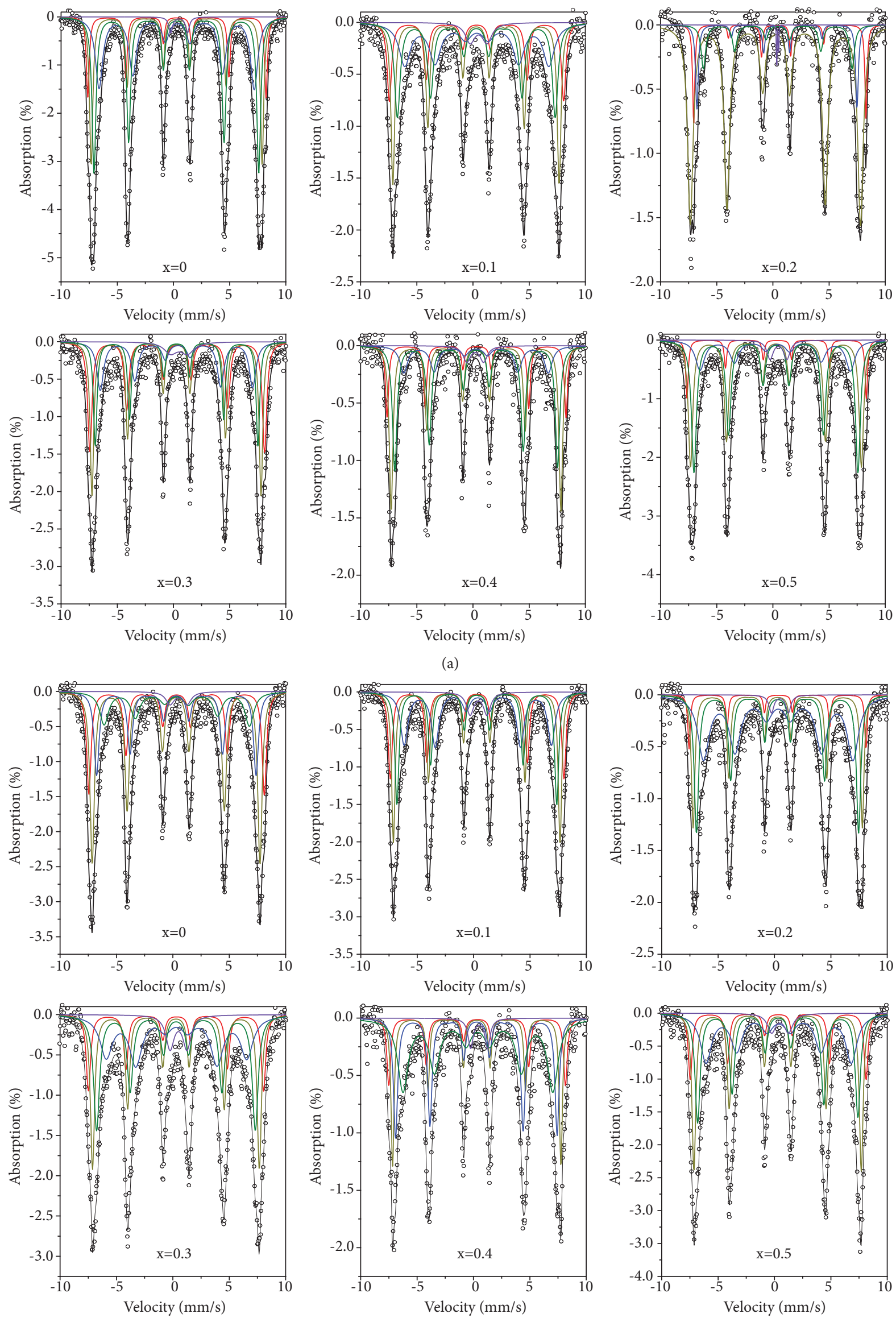

(b)

Figure 4: Mössbauer spectra of (a) furnace-cooled and (b) quenched $\mathrm{Mg}_{1-\mathrm{x}} \mathrm{Cu}_{\mathrm{x}} \mathrm{Fe}_{2} \mathrm{O}_{4}(x=0-0.5)$ samples. 
TABLE 3: Mossbauer parameters for furnace-cooled and quenched $\mathrm{Mg}_{1-\mathrm{x}} \mathrm{Cu}_{\mathrm{x}} \mathrm{Fe}_{2} \mathrm{O}_{4}$ samples after sintering at $1200^{\circ} \mathrm{C}$.

\begin{tabular}{|c|c|c|c|c|c|c|c|c|c|}
\hline \multirow{2}{*}{$\begin{array}{l}\text { Copper } \\
\text { content }\end{array}$} & \multirow{2}{*}{$\begin{array}{c}\text { Site } \\
\text { occupancy }\end{array}$} & \multicolumn{2}{|c|}{ Isomer shift, $\delta(\mathrm{mm} / \mathrm{s})$} & \multicolumn{2}{|c|}{$\begin{array}{l}\text { Quadrupole splitting, QS } \\
(\mathrm{mm} / \mathrm{s})\end{array}$} & \multicolumn{2}{|c|}{ Hyperfine field, $\mathrm{H}_{\mathrm{hf}}(\mathrm{kG})$} & \multicolumn{2}{|c|}{ Relative area, A (\%) } \\
\hline & & $\begin{array}{c}\text { Furnace- } \\
\text { cooled }\end{array}$ & Quenched & $\begin{array}{c}\text { Furnace- } \\
\text { cooled }\end{array}$ & Quenched & $\begin{array}{c}\text { Furnace- } \\
\text { cooled }\end{array}$ & Quenched & $\begin{array}{l}\text { Furnace- } \\
\text { cooled }\end{array}$ & Quenched \\
\hline \multirow{4}{*}{$x=0.0$} & $\mathrm{~B}$ & 0.330 & 0.314 & 0.232 & 0.080 & 493.583 & 483.181 & \multirow{2}{*}{61.9} & \multirow{2}{*}{61.8} \\
\hline & $\mathrm{B}$ & 0.286 & 0.265 & 0.000 & 0.000 & 473.591 & 460.300 & & \\
\hline & $\mathrm{A}$ & 0.330 & 0.251 & 0.431 & 0.499 & 429.129 & 389.011 & \multirow{2}{*}{38.1} & \multirow{2}{*}{38.2} \\
\hline & $\mathrm{A}$ & 0.262 & 0.331 & 0.000 & 0.828 & 456.518 & 430.809 & & \\
\hline \multirow{4}{*}{$x=0.1$} & $\mathrm{~B}$ & 0.383 & 0.316 & 0.362 & 0.000 & 479.924 & 479.369 & \multirow{2}{*}{61.1} & \multirow{2}{*}{62.4} \\
\hline & $\mathrm{B}$ & 0.428 & 0.278 & 0.152 & 0.000 & 475.169 & 460.032 & & \\
\hline & $\mathrm{A}$ & 0.459 & 0.375 & 0.444 & 0.000 & 450.737 & 406.684 & \multirow{2}{*}{38.9} & \multirow{2}{*}{37.6} \\
\hline & $\mathrm{A}$ & 0.273 & 0.290 & 0.433 & 0.000 & 363.255 & 441.204 & & \\
\hline \multirow{4}{*}{$x=0.2$} & B & 0.452 & 0.314 & 0.499 & 0.191 & 468.198 & 488.309 & \multirow{2}{*}{61.8} & \multirow{2}{*}{62.8} \\
\hline & B & 0.260 & 0.291 & 0.293 & 0.000 & 471.252 & 466.933 & & \\
\hline & $\mathrm{A}$ & 0.349 & 0.337 & 0.037 & 0.000 & 438.897 & 412.492 & \multirow{2}{*}{38.2} & \multirow{2}{*}{37.2} \\
\hline & A & 0.434 & 0.277 & 0.000 & 0.020 & 412.217 & 447.696 & & \\
\hline \multirow{4}{*}{$x=0.3$} & B & 0.323 & 0.308 & 0.009 & 0.202 & 490.436 & 483.249 & \multirow{2}{*}{61.8} & \multirow{2}{*}{63.1} \\
\hline & B & 0.272 & 0.274 & 0.000 & 0.000 & 468.369 & 460.480 & & \\
\hline & A & 0.324 & 0.321 & 0.216 & 0.269 & 415.907 & 387.688 & \multirow{2}{*}{38.2} & \multirow{2}{*}{36.9} \\
\hline & A & 0.282 & 0.279 & 0.000 & 0.020 & 450.879 & 438.040 & & \\
\hline \multirow{4}{*}{$x=0.4$} & B & 0.339 & 0.344 & 0.080 & 0.090 & 495.884 & 487.695 & \multirow{2}{*}{62.4} & \multirow{2}{*}{63.8} \\
\hline & B & 0.273 & 0.294 & 0.000 & 0.000 & 470.346 & 464.775 & & \\
\hline & $\mathrm{A}$ & 0.276 & 0.265 & 0.000 & 0.462 & 400.490 & 445.160 & \multirow{2}{*}{37.6} & \multirow{2}{*}{36.2} \\
\hline & $\mathrm{A}$ & 0.291 & 0.393 & 0.388 & 0.008 & 450.624 & 413.646 & & \\
\hline & B & 0.369 & 0.343 & 0.138 & 0.050 & 496.815 & 485.470 & & \\
\hline$x=05$ & B & 0.278 & 0.281 & 0.000 & 0.070 & 473.511 & 462.075 & 62.9 & 63.3 \\
\hline$x=0.5$ & A & 0.323 & 0.378 & 0.757 & 0.000 & 414.853 & 401.219 & & \\
\hline & A & 0.276 & 0.303 & 0.000 & 0.738 & 454.298 & 440.170 & 37.1 & 36.7 \\
\hline
\end{tabular}

the furnace-cooled sample. The decrease of coercivity is due to the increases of particle size with $\mathrm{Cu}$ doping. However, no significant effect of quenching on coercivity and remanent magnetization is evident. The squareness ratio $\left(M_{\mathrm{r}} / M_{\mathrm{s}}\right)$ of the hysteresis loop is an essential parameter of determining the domain state. The squareness ratio less than 0.5 indicates the formation of a multidomain state and equal to or above 0.5 refers that the particles are in the single domain state $[34,35]$. The value of squareness ratio in the range $0.06-0.23$ and $0.05-0.11$ for furnace-cooled and quenched samples, respectively, suggested that the samples belong to the multidomain state.

3.4. Mössbauer Study. The Mössbauer spectra of furnacecooled and quenched $\mathrm{Mg}_{1-\mathrm{x}} \mathrm{Cu}_{\mathrm{x}} \mathrm{Fe}_{2} \mathrm{O}_{4}(x=0.0-0.5)$ ferrites are shown in Figures 4(a) and 4(b) and were measured at room temperature. The spectral parameters, such as isomer shift $(\delta)$, quadruple shift (QS), and hyperfine field $\left(\mathrm{H}_{\mathrm{hf}}\right)$, are computed and summarized, as given in Table 3. All samples show very well-resolved four sextets. The cation distributions at tetrahedral (A) and octahedral (B) are calculated based on the relative area of each component. The sextet pattern results from the interaction of the nuclear ${ }^{57} \mathrm{Fe}$ magnetic moment with the electromagnetic field. The appearance of the sextet is characteristics of magnetically ordered ferrimagnetic materials.

The values of the isomer shift in Table 3 are quoted relative to the metallic iron at room temperature. The isomer shifts arise due to the Columbic interaction between the nuclear charge density and the surrounding S-electron cloud, causing a slight shift of the centroid position of the Mössbauer spectrum and varies with a different composition of $\mathrm{Mg}-\mathrm{Cu}$ ferrites. The range of isomer shift $(\delta)$ of the $\mathrm{Fe}$ atom at $A$ and $B$ sites is observed between 0.260 and $0.459 \mathrm{~mm} / \mathrm{s}$ for furnace-cooled and 0.265 and $0.393 \mathrm{~mm} / \mathrm{s}$ for quenched samples, indicating all samples are in highspin Fe (III) oxidizing state [36]. The minimal change in the value of the isomer shift suggests that the $\mathrm{Cu}$ substitution and cooling process barely impact the S-electron distribution of $\mathrm{Fe}^{3+}$. The quadrupole shift (QS) is a measure of how the electric field gradient around the atom affects the atom's nuclear energy levels. The electric quadrupole interaction between the quadrupole moment of the nucleus and the electric field gradient of electrons in the nucleus leads to quadrupole shift (QS). The QS of the Fe atoms at A and B sites is observed in the range of $0.00-0.757 \mathrm{~mm} / \mathrm{s}$ and $0.00-0.828 \mathrm{~mm} / \mathrm{s}$ for furnace-cooled and quenched samples. It is also observed that the nonzero quadrupole splitting values of $\mathrm{A}$ and $\mathrm{B}$ sites are varying randomly with $\mathrm{Cu}$ content, which suggests the presence of chemical disorder due to the arbitrary distribution of $\mathrm{Cu}^{2+}$ ions around $\mathrm{Fe}^{3+}$ ions. The mean hyperfine field values acting on $\mathrm{A}$ and $\mathrm{B}$ sites are essentially independent of $\mathrm{Cu}$ content and cooling conditions. Apparently, the mean hyperfine field values for the octahedral sites are higher compared to the tetrahedral sites. This is because $\mathrm{Fe}^{3+}-\mathrm{O}^{2-}$ bonds at tetrahedral sites are more covalent in nature than that of the octahedral sites [37]. 
With the increase of $\mathrm{Cu}^{2+}$ content, the relative area of the $\mathrm{B}$ site increases due to moving the $\mathrm{Fe}^{3+}$ ions from $\mathrm{A}$ site to $\mathrm{B}$ site. Moreover, the quenched samples possess a higher relative area on the $\mathrm{B}$ site compared to the furnace-cooled samples except for the case of $x=0$.

\section{Conclusion}

The influence of the $\mathrm{Cu}$ content and quenching after sintering on microstructure and magnetic properties of $\mathrm{Mg}-\mathrm{Cu}$ ferrite has been focused on in this study. The X-ray diffraction analysis for $1100^{\circ} \mathrm{C}$ revealed the formation of a single-phase cubic spinel structure with no secondary phase. Two different processes of cooling after sintering at $1200^{\circ} \mathrm{C}$ exhibited different microstructures and magnetic behaviors. SEM result clearly showed that the microstructure of the samples was highly influenced by the addition of $\mathrm{Cu}$ and the cooling process. All samples demonstrated soft magnetic behavior, and saturation magnetization was relatively higher for the quenched samples compared with the furnace-cooled samples. Mössbauer spectroscopy confirmed all samples were ferromagnetic. Magnetic hyperfine parameters measured by Mössbauer spectroscopy showed that hyperfine parameters vary randomly with $\mathrm{Cu}^{2+}$ and the cooling process. This works shows that water quenching may result in the fabrication of high saturation $\mathrm{Mg}$ - $\mathrm{Cu}$ ferrite for soft magnetic applications.

\section{Data Availability}

The authors declare that the data used to support the findings of this study are included within the article.

\section{Conflicts of Interest}

The authors declare that they have no conflicts of interest.

\section{Acknowledgments}

The authors are grateful to the Atomic Energy Center, Dhaka, and Department of Physics, Khulna University of Engineering and Technology, Khulna, for the support provided to perform this experiment.

\section{References}

[1] M. Sugimoto, "The past, present, and future of ferrites," Journal of the American Ceramic Society, vol. 82, pp. 269-280, 1999.

[2] A. L. Stuijts, J. Verweel, and H. P. Peloschek, "Dense ferrites and their applications," IEEE Transactions on Consumer Electronics, vol. 83, no. 75, pp. 726-736, 1964.

[3] M. Pardavi-Horvath, "Microwave applications of soft ferrites," Journal of Magnetism and Magnetic Materials, vol. 215216, pp. 171-183, 2000.

[4] A. Goldman, "Ferrites for permanent magnet applications," in Modern Ferrite Technology, pp. 227-242, Springer, Boston, MA, USA, 2006.

[5] S. Halder, S. I. Liba, A. Nahar, S. S. Sikder, and S. M. Hoque, "To study the surface modified cobalt zinc ferrite nanoparticles for application to magnetic hyperthermia," AIP Advances, vol. 10, no. 12, Article ID 125308, 2020.

[6] M. Irfan Hussain, M. Xia, Xiao-NaRen et al., "Ferrite nanoparticles for biomedical applications," Magnetic Nanoheterostructures, pp. 243-265, 2020.

[7] Y. M. Abbas, S. A. Mansour, M. H. Ibrahim, and S. E. Ali, "Microstructure characterization and cation distribution of nanocrystalline cobalt ferrite," Journal of Magnetism and Magnetic Materials, vol. 323, no. 22, pp. 2748-2756, 2011.

[8] A. Abu El-Fadl, A. M. Hassan, and M. A. Kassem, "Tunable cationic distribution and structure-related magnetic and optical properties by $\mathrm{Cr} 3+$ substitution for $\mathrm{Zn} 2+$ in nanocrystalline Ni-Zn ferrites," Results in Physics, vol. 28, Article ID 104622, 2021.

[9] I. C. Nlebedim, N. Ranvah, P. I. Williams et al., "Effect of heat treatment on the magnetic and magnetoelastic properties of cobalt ferrite," Journal of Magnetism and Magnetic Materials, vol. 322, pp. 1929-1933, 2010.

[10] I. C. Nlebedim, Y. Melikhov, and D. C. Jiles, "Temperature dependence of magnetic properties of heat-treated cobalt ferrite," Journal of Applied Physics, vol. 115, 2014.

[11] G. A. Sawatzky, F. van der Woude, and A. H. Morrish, "Mössbauer study of several ferrimagnetic spinels," Physical Review, vol. 187, no. 2, pp. 747-757, 1969.

[12] O. Mounkachi, M. Hamedoun, M. Belaiche et al., "Synthesis and magnetic properties of ferrites spinels MgxCu1-xFe2O4," Physica B: Condensed Matter, vol. 407, no. 1, pp. 27-32, 2012.

[13] H.-I. Hsiang and J.-L. Wu, "Cooling rate effects on the microstructure, magnetic properties, and DC superposition behavior of NiCuZn ferrites," International Journal of Applied Ceramic Technology, vol. 12, no. 5, pp. 1065-1070, 2015.

[14] J. Gutiérrez-López, N. Masó, B. Levenfeld, A. Várez, and A. R. West, "Electrical and magnetic properties of NiZn ferrite prepared by conventional and solar sintering," Journal of the American Ceramic Society, vol. 99, pp. 2327-2333, 2016.

[15] H. Roy Dakua, N. Venkataramani, and S. Prasad, "Effect of quenching on the magnetic properties of $\mathrm{Mg}$-ferrite thin films," AIP Advances, vol. 6, no. 5, Article ID 055919, 2016.

[16] A. Hajalilou and S. A. Mazlan, "A review on preparation techniques for synthesis of nanocrystalline soft magnetic ferrites and investigation on the effects of microstructure features on magnetic properties," Applied Physics A: Materials Science \& Processing, vol. 122, 2016.

[17] S. F. Shaikh, M. Ubaidullah, R. S. Mane, and A. M. Al-Enizi, "Types, Synthesis methods and applications of ferrites," in Micro and Nano Technologies, R. S. Mane and V. V. B. T.-S. F. N. for E. S. D. Jadhav, Eds., Elsevier, Amsterdam, Netherlands, pp. 51-82, 2020.

[18] T. Kiseleva, V. Kabanov, A. Ilyushin, G. Markov, D. Sanga, and H. Hirazawa, "Structural and magnetic properties of copper substituted Mg-ferrites," EPJ Web of Conferences, vol. 185, pp. 1-5, 2018.

[19] E. Ateia, M. A. Ahmed, and R. M. Ghouniem, "Electrical properties and initial permeability of $\mathrm{Cu}-\mathrm{Mg}$ ferrites," Solid State Sciences, vol. 31, pp. 99-106, 2014.

[20] S. Akhter, D. P. Paul, S. Akhter, D. K. Saha, S. M. Hoque, and M. A. Hakim, "Structural, magnetic and electrical properties of cu-mg ferrites," Journal of Scientific Research, vol. 6, no. 2, 2014.

[21] A. Marais and T. Merceron, "Orientation superstructures and their effects in spinel ferrites," Physica Status Solidi (B), vol. 24, no. 2, pp. 635-649, 1967.

[22] S. Akhter, D. P. Paul, S. M. Hoque, and M. A. Hakim, "Thermal effects on electromagnetic properties of $\mathrm{Cu} 1-\mathrm{x} \mathrm{Mg} \mathrm{x}$ 
Fe2O4 ferrites," International Journal of Materials Research, vol. 108, no. 9, pp. 776-779, 2017.

[23] A. Balamurugan, R. S. Priya, P. Chaudhary et al., "Natural fuel assisted synthesis of $\mathrm{Mg}$-Cu ferrite nanoparticles: evaluation of structural, dielectric, magnetic and humidity sensing properties," Ceramics International, vol. 48, no. 4, pp. $4874-4885,2022$.

[24] C. Sujatha, K. V. Reddy, K. S. Babu, A. R. Reddy, and K. H. Rao, "Effects of heat treatment conditions on the structural and magnetic properties of $\mathrm{MgCuZn}$ nano ferrite," Ceramics International, vol. 38, no. 7, pp. 5813-5820, 2012.

[25] J. Kurian and M. J. Mathew, "Structural, magnetic and mossbauer studies of magnesium ferrite nanoparticles prepared by hydrothermal method," International Journal of nanoscience, vol. 17, no. 1-2, pp. 1-6, 2018.

[26] T. F. Marinca, I. Chicinaş, and O. Isnard, "Structural and magnetic properties of the copper ferrite obtained by reactive milling and heat treatment," Ceramics International, vol. 39, no. 4, pp. 4179-4186, 2013.

[27] O. M. Hemeda and M. M. Barakat, "Effect of hopping rate and jump length of hopping electrons on the conductivity and dielectric properties of Co-Cd ferrite," Journal of Magnetism and Magnetic Materials, vol. 223, no. 2, pp. 127-132, 2001.

[28] M. Ajmal and A. Maqsood, "Structural, electrical and magnetic properties of Cu1-xZnxFe2O4 ferrites $(0 \leq \mathrm{x} \leq 1)$," Journal of Alloys and Compounds, vol. 460, no. 1-2, pp. 54-59, 2008.

[29] T. Abbas, M. U. Islam, and M. Ashraf, "Study of sintering behavior and electrical properties of $\mathrm{Cu}-\mathrm{Zn}-\mathrm{Fe}-\mathrm{O}$ system," Modern Physics Letters B, vol. 9, no. 22, pp. 1419-1426, 1995.

[30] S. S. Bellad, S. C. Watawe, and B. K. Chougule, "Microstructure and permeability studies of mixed Li-Cd ferrites," Journal of Magnetism and Magnetic Materials, vol. 195, no. 1, pp. 57-64, 1999.

[31] J. Li, X. Wang, K. Song et al., "High magnetic loss $\mathrm{Mg}-\mathrm{Cu}$ ferrites for ultrahigh frequency EMI suppression applications," IEEE Transactions on Magnetics, vol. 51, pp. 8-11, 2015.

[32] M. Manjurul Haque, M. Huq, and M. A. Hakim, "Effect of $\mathrm{Zn} 2+$ substitution on the magnetic properties of Mg1-xZnxFe2O4 ferrites," Physica B: Condensed Matter, vol. 404, no. 21, pp. 3915-3921, 2009.

[33] K. K. Bamzai, G. Kour, B. Kaur, and S. D. Kulkarni, "Preparation, and structural and magnetic properties of $\mathrm{Ca}$ substituted magnesium ferrite with composition MgCaxFe2-xO4 ( $\mathrm{x}=0.00,0.01,0.03,0.05,0.07)$," Journal of $\mathrm{Ma}-$ terials, vol. 2014, Article ID 184340, 8 pages, 2014.

[34] R. Skomski and J. M. D. Coey, Permanent Magnetism, 1999.

[35] U. Topal, H. Ozkan, and H. Sozeri, "Synthesis and characterization of nanocrystalline $\mathrm{BaFe} 12 \mathrm{O} 19$ obtained at $850^{\circ} \mathrm{C}$ by using ammonium nitrate melt," Journal of Magnetism and Magnetic Materials, vol. 284, pp. 416-422, 2004.

[36] B. Fultz, Mössbauer Spectrometry, Characterization of Materials, pp. 1-21, 2012.

[37] M. Almokhtar, A. M. Abdalla, and M. A. Gaffar, "Phase analysis study of copper ferrite aluminates by X-ray diffraction and Mössbauer spectroscopy," Journal of Magnetism and Magnetic Materials, vol. 272-276, pp. 2216-2218, 2004. 